\title{
Medidas de silêncio e voz: a presença feminina em La Noire de... e em Contra a parede
}

\section{Silencing and voicing procedures: the female presence in La noire de... and in Against the wall}

https://doi.org/10.34112/2317-0972a2017V35n70p51-66

\section{FERNANDA RIOS ${ }^{1}$}

Claudia Dornbusch ${ }^{2}$

Resumo: O objeto de estudo deste artigo são os filmes La Noire de... (1966), do senegalês Ousmane Sembène, e Contra a parede (2004), do turco-alemão Fatih Akin. Ambos serão analisados segundo aspectos narrativos (enredo e construção da personagem feminina) e da temática (a mulher no contexto imigratório), buscando interpretar as diferentes perspectivas de Diouana e de Sibel, quanto à sua inserção em instâncias de poder e sua(s) voz(es) e silêncio(s). Palavras-chave: La Noire de...; Ousmane Sembène; França; África; Contra a parede; Fatih Akin; Turquia; Alemanha.

ABStRACt: This article analyses the films La Noire de ... (1966), by the Senegalese Ousmane Sembène, and Against the Wall (2004), by the Turkish-German Fatih Akin. Both will be studied according to narrative aspects (plot and construction of the female character) and theme (the woman in the immigrant context), seeking to interpret the different perspectives of Diouana and Sibel as to their insertion in instances of power and their voice(s) and silence(s).

Keywords: La Noire de...; Ousmane Sembène; França; África; Against the Wall; Fatih Akin; Turquia; Alemanha.

1. Universidade de São Paulo, São Paulo, SP, Brasil.

2. Universidade de São Paulo, São Paulo, SP, Brasil. 
Medidas de silêncio e voz: a presença feminina em La Noire de... e em Contra a parede

INTRODUÇÃO

Talvez eu aí estivesse.

Roland Barthes

O filme La noire de... (1966), de Ousmane Sembène, conta a história de uma moça senegalesa que vai trabalhar em uma casa de família na França. Diouana sai de sua terra natal, deixando para trás mãe, irmão e namorado, em busca de um trabalho digno na badalada Riviera Francesa. Porém, sente-se em uma prisão, ao ver-se no papel de doméstica, ao invés do prometido cargo de babá. Ela e a patroa estabelecem uma relação doentia, que resulta em um final trágico. No turco-alemão Gegen die Wand (Contra a parede) (2004), a personagem Sibel procura um noivo descendente de turcos, para um casamento falso. Ela quer um marido "de fachada", para conseguir a tão sonhada liberdade. Então, conhece Cahit em uma clínica para tratamento de suicidas, onde ela também se recupera. Esse casamento torto possibilita a sua fuga das tradições de família. No entanto, é através desse caminho que eles acabam encontrando o amor.

Os curtas-metragens The Sonhrai Empire (1963) e Niaye (1964) foram as primeiras realizações do diretor senegalês. Após servir nas forças francesas, ele voltou a Dakar, influenciado pela Nouvelle Vague, e filmou La noire de...., o seu primeiro longa-metragem. Com esse filme, Sembène tornou-se o primeiro cineasta africano de relevância internacional e, por isso, é ainda hoje considerado o pai do cinema africano. E foi ainda com La noire de... que conquistou o prêmio Jean Vigo.

Akin tem ascendência turca: seus pais emigraram da Turquia para Hamburgo nos anos 1960. Por esse motivo, a população turca e seus descendentes na Alemanha são um tema recorrente em seu cinema. Contra a parede é um dos seus primeiros longas-metragens e retoma essa temática. Akin recebeu o "Urso de Ouro" em 2004 por essa realização. Foi a primeira vez em 18 anos que novamente um filme alemão venceu a Berlinale, um dos principais festivais europeus e o maior evento cinematográfico da Alemanha.

A principal razão para aproximar esses filmes tão diferentes entre si e bastante distantes cronologicamente é a presença de duas personagens femininas fortes, que buscam se estabelecer em sociedades opressoras, mesmo fazendo parte da minoria "dominada". Tateando à busca de um lugar para si nessas comunidades, elas acabam levantando a questão da própria identidade. Em La noire de..., Sèmbene confirma, 
através da cinematografia e da narrativa, as relações de poder estabelecidas durante a colonização e o modo como elas se transformam no período pós-colonização. Há, portanto, uma discussão histórica embutida no filme africano, que trata de questões de nação, identidade nacional e submissão, em oposição à individuação identitária. Em território africano, onde vários paísesse submeteram ao jugo estrangeiro, acaba alcançando destaque também a questão da língua oficial de cada país. As relações de convívio entre estrangeiro-senhor e nativo-subjugado são transportadas, no filme, para uma realidade pós-colonial, em que a necessidade de uma nova identidade fica evidente a partir de um conflito senhora-funcionária.

Já em Contra a parede, a relação não é de colonização, mas de certo "acomodamento" das tradições turcas na sociedade alemã. Os turcos foram para a Alemanha como trabalhadores convidados, ou seja, pelo menos oficialmente eles não deveriam nada aos seus empregadores alemães. Porém, vimos, através de Sibel, uma turco-alemã que quer se estabelecer em seu país natal, que se desvencilhar dessas raízes não seria uma simples escolha individual. Em uma resenha publicada na revista Spiegel (2004), Oliver Hüttmann aponta que os turcos agora já são a terceira geração que nasceu e cresceu na Alemanha e, por isso, começam a se identificar com essas raízes alemãs, que também já são suas. No entanto, o filme não discute a questão como pedagogia social a favor dos imigrantes, mas como algo inerente ao cotidiano, presente de maneira silenciosa, contínua e quase imperceptível.

Se, por um lado, observamos aproximações entre essas duas películas, também destacamos diferenças. O filme africano foi filmado há 46 anos em preto e branco. Em relação à temática, apesar de Diouana sair do Senegal rumo à França, sua trajetória não inclui muitas ações. O filme passa-se quase inteiramente em um apartamento, chegando a oferecer ao espectador uma sensação claustrofóbica. No filme alemão também há uma viagem. Sibel foge para a Turquia e Cahit vai ao seu encontro. Porém, a vastidão do trajeto e das paisagens significa que a personagem Sibel está solitária, quase abandonada nesse momento. O filme data de 2004; é colorido e já representa a vida em duas grandes cidades: uma alemã e uma turca.

O objetivo do presente trabalho é analisar, através de algumas cenas de Contra $a$ parede e La Noire de..., de que maneira a mulher se insere em instâncias de poder, seja em contraposição ao universo masculino, seja no âmbito de suas próprias tradições e sociedades. Vale ressaltar que, apesar de Sibel não ser a protagonista única (como é Diouana em La Noire de...) de Contra a parede, é através de um pedido dela que a ação se desenvolve. Além disso, discutiremos brevemente a noção de nação inserida 
no contexto dos filmes e como os cineastas construíram seus filmes no intuito de debater esses pontos.

A NOÇÃO DE NAÇÃO: O CORPO, A FEMINILIZAÇÃO E O CICLO

We are what you were; we will be what you are

Canção espartana ${ }^{3}$

Para Benedict Anderson, nação é uma coletividade que estabelece relações políticas, é soberana, possui fronteiras delimitadas e, principalmente, é uma sociedade imaginada. Ou seja, um determinado povo constituiria uma nação quando há um governo comum (não necessariamente democrático), quando possui fronteiras delimitadas e existe uma ideia de que as características determinantes são habituais e comuns a todos. Seus habitantes mantêm tradições, compartilham pensamentos e acontecimentos. Em relação aos dois filmes objetos de estudo, é difícil enquadrar a ideia de nacionalidade nesses dois contextos. Qual seria a nação de Sibel, que nasceu na Alemanha, mas tem raízes turcas? Ela vive imersa em uma ilha de tradições turcas em uma grande cidade alemã. No entanto, Sibel não vê o momento em que poderá se libertar dessas tradições. Assim que se casa com Cahit, suas primeiras atitudes são cortar o cabelo e colocar piercings. Desde o início do filme, Sibel afirma que um dos seus sonhos é operar o nariz, marca distintiva de sua nacionalidade turca. Isto é, ela quer amenizar seu traço mais característico para não ser facilmente identificada como estrangeira no universo germânico. Posteriormente, na vida real, a atriz Sibel Kekilli usou o cachê do filme para fazer uma cirurgia plástica que amenizasse esses traços.

No universo feminino do filme, destaca-se ainda na trama o papel da mãe de Sibel, Birsen. Ela tenta avisar à filha constantemente que a melhor forma de contornar as proibições da tradição é aceitando-as e descobrindo as brechas que oferecem. Birsen casou-se com um patriarca turco e mudou-se para a Alemanha. Lá, aprendeu a cortar os cabelos, tingi-los e, ainda por cima, aprendeu a fumar. Fica evidente que indiretamente Birsen desafia as imposições do marido. No entanto, ainda está presa ao círculo familiar. Aprendeu a lidar com as diversas possibilidades dentro de sua própria casa. Já Sibel é o resultado desse desafio. Ela quer ir além dos limites que a

3. "Nós somos o que vocês foram; nós seremos o que vocês são." (RENAN apud BHABHA, 2004, p. 19, tradução livre). 
mãe conseguiu para si. Assim, Sibel almeja abandonar o "exotismo" de suas raízes em busca da ocidentalização de seus traços.

Em La Noire de... , acompanhamos um processo semelhante. Nas cenas em que Diouana aparece em casa, usa roupas africanas. Quando chega à Riviera Francesa, já parece tornar-se uma madame ocidental (europeia?). Tenta se adequar ao vestuário da patroa e de suas amigas, chegando até mesmo a alterar a configuração de seu cabelo, notadamente mantido em estilo afro. O processo inverso de "reafricanização" somente acontece quando ela se vê em um espaço não somente estrangeiro, mas também estranho aos seus conceitos. Ela sai da casa de sua mãe, acreditando que em outra nação terá oportunidades que não teve em sua própria. No entanto, o que descobre em terras francesas é que o cargo de babá, as belas praias e a chance de crescer, na verdade, concretizam uma prisão em um apartamento pequeno e solitário.

No filme africano, Diouana, após ver as suas expectativas sendo frustradas e as esperanças se esvaindo, volta a enxergar como nação a sua terra natal, o Senegal, onde estão seu irmão, sua mãe e seus princípios. A máscara, nesse momento, passa a ser não apenas um símbolo africano, mas também representa a terra-mãe e a boa hospitalidade de seu país e, principalmente, faz as vezes de um sonho desperdiçado. Ressalte-se ainda que os embates em La Noire de... encontram-se plasmados nas oposições entre as duas mulheres, reveladas em polaridades: patroa/empregada, branca/negra, europeia/africana, francesa/senegalesa, colonizadora/ex-colonizada. Diouana segue iludida, guiada pela francesa, que aparentemente a levará a um futuro diferente. No entanto, a francesa nada mais almeja que manter seu estatuto de poder inalterado. Segundo Debray (apud ANDERSON, 2008, p. 39): "Sim, é puro acaso que eu tenha nascido francês; mas, afinal, a França é eterna”. Isso demonstra a mentalidade francesa de que a França é superior aos países colonizados.

Encontramos, então, a ideia de um nacionalismo torpe, em que o mero fato de nascer em solo francês já torna o indivíduo melhor do que outro ser humano. Sobressai aqui o pensamento que, como destaca Anderson (2008), em Comunidades imaginadas, traz simultaneamente o insulto ao dominado e a exaltação ao acusador. Poderíamos entender tal postura como racista, se levarmos em consideração a definição de racismo de Albert Memmi (apud ANDERSON 2008, p. 45): "a atribuição generalizada de valor a diferenças reais ou imaginárias para o benefício do acusador sobre a vítima, com a finalidade de justificar o privilégio e a agressão do primeiro”.

Em Contra a parede, não se mostra um conflito de cunho maniqueísta exacerbado. Tanto o diretor e roteirista Fatih Akin quanto a protagonista Sibel já estão 
imersos nas duas tradições, e é impossível identificar se há uma cultura "vilã." Além disso, a língua usada por Sibel não é somente uma: na primeira parte do filme, quando quer conseguir seu espaço individual, ela fala com os pais em turco e com o mundo, em alemão. Sendo assim, a questão da nação atrelada à fala, ao idioma e à expressão mostra-se como um resultado da mescla de nações.

Segundo Anderson (2008), há três concepções que possibilitam estabelecer a imagem de uma nação. De acordo com a primeira, determinada língua (e a respectiva escrita) nos proporciona um caminho à verdade do nosso ser. Isto é, dependendo da língua que falamos, conseguimos expor determinados sentimentos e características individuais marcantes e, ao mesmo tempo, reforçamos a sensação de estarmos inseridos em um coletivo. Em outra passagem, Anderson observa de que maneira a língua foi uma das pontes para a transformação de territórios em nações: "Por sob o declínio das comunidades, línguas e linhagens sagradas estava ocorrendo uma transformação fundamental nos modos de apreender o mundo, a qual, mais do que qualquer outra coisa, possibilitou 'pensar' a nação" (ANDERSON, 2008, p. 52). Pela segunda concepção de Benedict Anderson, a sociedade se organiza em torno de governanças. $\mathrm{Na}$ época da formação da maioria das nações, elas seriam de ordem divina. A terceira é uma concepção cultural de temporalidade, segundo a qual as origens do mundo e do homem seriam as mesmas, e os homens não escapariam às "fatalidades diárias" (a morte, a perda e a servidão) (p. 69).

Vejamos, então, como essas concepções podem ser aplicadas às nossas personagens. A língua das mulheres-protagonistas nos filmes analisados torna-se elemento essencial para estudá-las, porque ambas se encontram no limiar de duas nacionalidades. Por um lado, como foi dito anteriormente, Sibel utiliza-se de uma língua para o universo doméstico e familiar e, por outro, aprendeu que há vida fora desse círculo e que, lá, a língua é outra. Parece evidente que, quando a personagem muda para a Turquia, muita coisa se passa e ela, retomando a ideia de família, volta também ao idioma turco. Portanto, individualidade e coletivo estão em constante confronto, se pensarmos nos termos da primeira concepção acima mencionada.

Já para Diouana, a relação com a língua é ainda mais complexa. Seria mais óbvio que Diouana se utilizasse de alguma língua africana falada no Senegal, como, por exemplo, o wolof. No entanto, Sembène apresenta-a praticamente monossilábica no filme e quase muda com os patrões. Porém, Diouana é de uma eloquência feroz em seu fluxo de consciência. A partir dessa aparente incongruência, o diretor faz com que a impossibilidade de comunicação, aliada à escolha da língua dos patrões, 
produza no espectador uma empatia ainda maior com a protagonista. Afinal, nós, enquanto plateia, tivemos acesso direto aos pensamentos altamente articulados da protagonista. É como se Sembène quisesse deixar escancarado que ela, apesar de proletária e colonizada, tem suas próprias vontades, suas razões e motivos para estar na Riviera Francesa, que vão além de saber limpar e cozinhar. A contradição de Diouana usar a língua dos colonizadores em seus pensamentos e não conseguir pronunciá-la, ressalta com vigor o aspecto da não comunicação, o que irá gerar conflitos decisivos. Também aqui, vemos a mescla de questões identitárias nacionais atreladas à língua e à expressão/não expressão.

Vejamos a questão da nação associada à governança, divina em sua origem, quando da formação da maioria das nações. Nos nossos dois casos, a França e a Alemanha já não eram mais monarquias, e o Senegal e a Turquia já se encontravam em posição subalterna em relação aos respectivos países-centro. Em ambos os casos, raramente as políticas governamentais ou as instâncias de poder aparecem no filme, sendo a polícia a única a representar o poder oficial nos países-centro: no filme de Akin, a polícia alemã, quando Cahit mata o amante de Sibel, provocando a separação do casal; no caso de Sembène, a polícia francesa, que investigaria o suicídio de Diouana.

Nos dois momentos, a polícia aparece depois do embate de duas nacionalidades. O turco Cahit mata Nico, o insolente amante alemão de sua mulher. Em La Noire de... Diouana, a africana subordinada, se mata diante das afrontas de sua patroa francesa. Assim, não geram dúvida o fato de que "a própria distribuição desigual de poder é que gera violência e separação, nem o fato de que o multiculturalismo pode oferecer uma visão mais igualitária das relações sociais" (SHOHAT; STAM, 2007, p. 86). Curiosamente, o título escolhido para o filme de Akin em Portugal foi A esposa turca. Enquanto no Brasil manteve-se a ideia poética e mórbida do título original Gegen die Wand/Contra a parede, em Portugal destaca-se a instituição do casamento no título do filme, além da nacionalidade da personagem, o que permite entender que a questão da nação e da identidade possa ter um apelo mais forte junto ao público europeu.

Cabe ressaltar que, quando falamos em governança e instâncias de poder, não nos referimos apenas a instâncias oficializadas, como a polícia, os órgãos governamentais, a Igreja. Falamos também nas instâncias de poder ancestralmente estabelecidas, como o patriarcado e o matriarcado ou tradições não escritas. No caso da família turca, vimos aqui a questão do que é permitido à mulher antes e depois de 
casada, quais as regras para um casamento. É desse universo do patriarcado, dessa instância de poder, que Sibel deseja fugir. No entanto, isso exigirá que ela se submeta a outras regras, que ela julga mais flexíveis, mas que - como veremos ao longo do filme - não são menos cruéis.

Em Contra a parede, no início do filme, Sibel procura um companheiro turco que aceite ser somente um marido de fachada. Ela quer curtir a vida e aproveitar tudo o que não teve enquanto esteve presa à casa paterna, às tradições e às repressões familiares. Depois de conhecer o amor por acidente e perder esse marido torto, ela resolve fugir para sua terra ancestral; e lá irá perceber o que realmente deseja: ter uma família. Isto é, o que realmente importa para ela é a estabilidade de um casamento com um homem mediano, mas bom, e a felicidade de sua filha. Para Diouana, por sua vez, a Riveira Francesa seria a única oportunidade de crescer e poder ajudar a sua família. Ela acredita que, indo à terra prometida, conseguirá tudo o que deseja. Porém, não tem em mente que, no suposto "paraíso", as regras do jogo podem ser outras. A protagonista, no início, ainda tenta se adaptar. Mas é no ritual da preparação de sua morte que revela sua real crença nos valores africanos.

Apresentam-se, portanto, simultaneamente, a questão da identidade e a temporalidade dos laços culturais, que perduram e retornam. Falamos aqui na dicção de Anderson, se pensarmos em morte, perda e servidão. Sibel percebe os seus reais anseios na Turquia a partir da perda daquele que seria o seu parceiro, mas que está preso por assassinato. Diouana desilude-se com a promessa de um futuro melhor, vivendo em uma relação de servidão - ao que poderíamos contrapor que a real liberdade era aquela em que vivia na sua nação, entendendo-se aqui a morte como saída contra o retrocesso.

O transcorrer do tempo fica evidente também na transformação vista nos corpos das protagonistas. Sibel começa com o cabelo longo, de adolescente. Ela coloca piercings e começa a usar roupas curtas e provocantes. Depois da separação, corta os cabelos como um protesto ou como a representação da perda da sexualidade. Já Diouana desmancha seu cabelo em estilo afro em prol da adaptação à vida europeia. Quando percebe que foi enganada, retoma as roupas e o cabelo africano.

Assim, a questão da nação está marcada também nos trajes e na apresentação física das personagens femininas. À medida que sofrem mudanças pessoais que vêm atreladas a experiências biculturais, a imagem que têm e que passam de si também se transforma, de acordo com a sua autossuficiência ou segurança, em termos de pertencimento a uma nação e/ou a um grupo cultural. 
A ideia de ciclo percorre os dois filmes. Em La noire de..., a quebra do sonho de Diouana faz com que ela confirme sua crença nos valores ancestrais, e a máscara que retorna a sua casa parece ser a materialização de sua volta ao lar. Diouana, por fim, retorna ao Senegal. Todos os ideais de Sibel são convertidos em ideais dos quais ela fugia quando morava na casa dos pais. Ela termina o filme na Turquia, mas sem esquecer suas raízes e sua vida alemã. Ambas as personagens estão imersas em situações-limite, das quais saem transformadas.

\section{As PROTAgONISTAS ENCENADAS NOS FILMES}

Considerando os aspectos acima arrolados, optamos por analisar duas sequências de cada filme: um trecho inicial, em que, de alguma maneira, a personagem feminina é apresentada, e uma cena final, em que acompanhamos seu desfecho. Não pretendemos apenas retratar o início e o resultado da trama, mas destacar cenas que representam mudanças nas personagens, como as tentativas de suicídio.

La Noire de... começa em um porto que, por si só, é um local de transição. Pessoas chegam e partem. Normalmente há o clima de nostalgia, despedidas e esperanças do que virá. Podemos dizer que Diouana está tomada por uma mescla desses sentimentos. A primeira imagem nos mostra a protagonista atravessando a passarela que liga o navio à costa. É um contra-plongée que sugeriria um enaltecimento da personagem. Em toda a sequência inicial, ela aparece como alguém importante. Cabe destacar também que, em um filme que sublinha o contraste preto e branco, apenas neste início há um trecho colorido.

Já no plano seguinte, vemos um close-up, com a personagem bem vestida, toda de branco, em contraste com a sua pele negra, usando brincos e colar. Ela olha ao redor, tentando reconhecer a paisagem. Ao longo de todo o filme, Diouana não usa muito o instrumento da fala (à exceção de um subserviente "Oui, monsieur"); é através de seu olhar que reconhecemos seus sentimentos e angústias e um breve momento com voz off: "Será que alguém virá me buscar?". No entanto, neste primeiro momento, ela ainda tenta reconhecer esse "novo território", talvez buscando um porto seguro para atracar.

O terceiro plano mostra o desembarque das pessoas do navio. Em um plano geral de ambientação, as pessoas se preparam para descer. Em seguida, Diouana, como ponto branco, cruza a tela, sempre com a mala em punho. A primeira palavra escrita que vemos na tela é Sortie (saída, em francês). Podemos afirmar que este é 
um filme estruturado em cima de escolhas da protagonista, sendo as saídas estritamente ligadas a essas escolhas. Diouana escolheu ir até a Riviera Francesa. Com o seu "fracasso", tomará a saída de volta, de maneira um tanto inusitada e trágica.

Em seguida, um homem de terno pega a sua mala e indica um carro. Em um primeiro momento, o homem parece ser o motorista de Diouana. Porém, confirmamos em seguida tratar-se de seu patrão. Ela entra no carro. Então, embarcamos com ela em uma sequência de reconhecimento da Riviera. Há uma alternância entre planos subjetivos de Diouana e planos do carro, que nos apresentam a França como um lugar próspero. Nos planos seguintes, conhecemos a casa de Diouana, sua terra natal, evidenciando a dissonância entre esses dois lugares. Há muito movimento nesta sequência inicial do filme, representando a distância percorrida por Diouana: primeiro, ela embarca em um navio rumo ao continente europeu; depois, é o automóvel que a leva do porto ao seu trabalho. Os meios de transporte são o modo de transposição de um mundo a outro.

Ao chegar, Diouana é enquadrada em close-up, olhando para o alto, e a câmera prolonga o momento em que observa a fachada do edifício, focando nos andares mais altos. Ela sabe que um desafio a espera. Porém, não desconfia ela que o apartamento representa um cárcere. $O$ patrão, mais uma vez, abre uma porta para ela. A máscara que ela ofereceu aos senhores já a espera na entrada da casa. Ela observa pela primeira vez a vista do apartamento, mal sabendo que seria sua última visão do mundo exterior. Fechando esse segmento inicial do filme, Diouana inicia seu serviço pela banheira branca e vazia da patroa.

O banheiro, lugar talvez mais íntimo de uma casa, é o ponto inicial de seu trabalho e também é o final de sua vida. Diouana vê na alva banheira o local oportuno para deitar seu corpo pela última vez. Focaremos nossa atenção nesta última parte desse ciclo. Por volta dos 46 minutos do filme, Diouana já está cansada da prisão domiciliar. Os planos no quarto são, em sua maioria, americanos e médios. A sensação de claustrofobia é evidenciada pelas dimensões do espaço e pelos enquadramentos. $\mathrm{O}$ patrão entra e lhe entrega dinheiro. Diouana deixa o dinheiro cair e se abaixa, chorando, quase em posição fetal. O quadro passa a ser um plongée, que representa a diminuição da personagem.

A patroa entra no quarto em busca da máscara, de que dera falta. Diouana imediatamente levanta-se, agarrando o símbolo de sua cultura. Elas giram no embate. O close-up dos rostos mostra a francesa lutando para ficar com o objeto e Diouana inabalável. O homem interfere, deixando Diouana com a máscara. Em seguida, 
com praticamente o mesmo enquadramento do começo da cena, Diouana faz sua mala. Ela guarda todas as roupas e fotos. Enfim, caminha até a sala, com a câmera a acompanhando em sua altura. Ela entrega o avental e o dinheiro de volta aos patrões. O patrão bebe e a patroa pinta as unhas. Com a câmera na altura de Diouana, os patrões ficam desvalorizados na posição sentada, com um tom que beira o ridículo.

Ela volta ao quarto e começa seu ritual de morte. Enrola o cabelo no penteado afro. Fecha a mala. A máscara cobre a mala, talvez representando tudo o que Diouana ainda preza. Através de outra câmera subjetiva, acompanhamos a moça em direção ao banheiro. Ela deita seu corpo negro e nu na banheira descorada. $\mathrm{O}$ diretor enquadra a moça de corpo inteiro, privilegiando a visão da cabeça. Vemos Diouana soltando a navalha que usou para se cortar. O plano detalhe do instrumento evidencia a morbidez da cena. A montagem feita nos leva à mesma disposição dos corpos em trajes de banho em uma praia da Riviera. Diferentemente de Diouana, lá as moças procuram se bronzear ao sol. A trilha é alegre, crianças brincam. Enfim, a vida continua, e a triste história da moça negra vira manchete de jornal "Une jeune négresse se tranche la gorge dans la salle de bains de ses patrons ${ }^{4}$.

Encontramos a notícia em um zoom-in. Alternando a distância focal, esse tipo de plano oferece ao espectador a urgência de uma revelação. A câmera permanece alguns segundos no jornal, possibilitando ao espectador a leitura da matéria. Segundo Langford (2014), é muito significativo que Diouana se suicide cortando a garganta, pois se afirma que Diouana se matou devido à impossibilidade de se comunicar com os patrões. Nós, afinal, sabemos não ter sido esta a única razão, mas sabemos ter sido ela um grande passo rumo à autodestruição.

Já em Contra a parede, o filme praticamente começa com os protagonistas Sibel e Cahit, ambos de origem turca, se conhecendo em uma clínica para suicidas na Alemanha. Sibel usa o suicídio para sair de uma cultura patriarcal, em que as vontades e os desejos da mulher são silenciados. Cahit é um viúvo que não vê mais sentido em viver. Ele joga o carro contra uma parede. Assim, é levado para a clínica, onde conhece Sibel. Cahit está na sala de espera do psicólogo da clínica. Um plano fechado mostra as ataduras nos punhos, a câmera sobe, corrigindo para o rosto de Sibel. O olhar dela está em Cahit. O médico chama por ele. Quando ele sai do consultório, Sibel o segue, assim como a câmera segue os dois. Ela pergunta a ele se é turco e, surpreendentemente, se ele se casaria com ela. Esta seria a forma de a

4. “Uma jovem negra corta a garganta no banheiro de seus patrões.” (tradução livre). 
família aceitá-lo (pois é turco) e ela se libertar da opressão patriarcal e entrar em um mundo de livres escolhas, tendo voz. Cahit acha que ela é louca e a manda sair. Eles se encontram novamente em um plano aberto, em um dos caminhos da clínica. Cahit anda mal-humorado. Sibel entra em quadro, alcançando-o. Ele diz que só transa com homens, e ela responde que isso é ainda melhor. Eles combinam um encontro à noite, porque Cahit quer uma cerveja.

À noite, vemos ambos no bar, tomando cerveja. Sibel aparece em close, maquiada e arrumada. Cahit pergunta por que ela tentou se matar. Ela tenta desviar da pergunta, dizendo que quer viver, mas antes precisa ser livre. Fala para ele tocar o seu nariz (que foi quebrado pelos irmãos) e seus seios. Cahit recusa. Pela primeira vez, eles aparecem em plano e contraplano. E o plano só fica aberto quando Cahit nega mais uma vez o pedido de casamento de Sibel. Ela, em um momento de fúria, corta os pulsos mais uma vez. O sangue jorra, espantando os clientes do bar.

Ambos voltam para a clínica em um ônibus. A cena tem uma câmera parada, em que estão separados pelo vão central do ônibus. Eles discutem a loucura de Sibel. A cena é surreal, beirando o cômico. Finalmente, o motorista expulsa os "cachorros" turcos do ônibus, porque o transporte é um bem da cidade e não deles. Depois desse episódio, Cahit pede Sibel em casamento aos pais. Eles vivem as desventuras desse matrimônio até Cahit matar Nico, um dos amantes de sua esposa. Sibel ainda tenta se matar mais uma vez, quando está na Turquia, desesperada e sem Cahit. Porém, somente quando a ordem já está restabelecida, Cahit volta a encontrar Sibel.

Nessas cenas iniciais, monta-se o universo cultural das personagens, que transitam entre a Alemanha e a Turquia. A família de Sibel vive na Alemanha há algum tempo, mantendo tradições familiares patriarcais, em que os irmãos vigiam a irmã solteira como cães de guarda. A mãe da protagonista feminina, como vimos anteriormente, tenta mostrar à filha que há meios de ser livre dentro da tradição. A comunicação entre elas muitas vezes é eloquente sem palavras, bastando olhares e gestos. No entanto, Sibel precisa se libertar, entrando no casamento de fachada com Cahit. Ficamos sabendo, porém, que a relação que começou como uma encenação acaba se tornando de grande afeto e amor.

Nas cenas finais do filme, Sibel está na Turquia, onde iniciou uma nova vida. Como vimos antes, Cahit havia sido preso. Depois de cumprir a pena, vai à busca de Sibel. Encontram-se em um quarto de hotel que, assim como no filme de Sembène, retrata um espaço de transição e de passagem. Esse encontro dos dois foi filmado em plano e contraplano. Durante esse jogo de quadros, planejam a fuga. Afinal, Sibel 
arrumou um marido turco e agora tem uma filha. Eles aparecem nessa sequência quase o tempo inteiro nus, despidos de toda a história anterior. A Sibel adolescente e falante deu lugar a uma mulher de cabelos curtos, silenciosa e pensativa. O último plano em que aparecem juntos mostra ambos refletidos no espelho em um plano médio. Temos, então, a impressão de que estão olhando para o que já foi ou o que já foram. Depois, ficamos sabendo que Sibel não vai ao encontro de Cahit. Ela prefere ficar com o marido para poder cuidar da filha. Cahit, com a recusa da amada, entra no ônibus rumo a sua cidade natal em busca de um recomeço. Novo espaço de transição e retorno ao universo bicultural ao qual Cahit estava acostumado.

Nessas sequências finais, percebemos o emudecimento e o aumento dos silêncios da personagem feminina. Ela, um reflexo do que foi no passado, em busca de seu amado que conhece a situação de viver entre duas nações, precisa tomar uma decisão. Opta pelo país de sua cultura de origem, a Turquia, mesmo que isso a leve ao silenciamento de suas emoções.

A Mulher COMo Ser (IN)visível

Manche Nebelflecken löset kein Auge auf.s

Na grande maioria das sociedades, a mulher ainda sofre uma série de repressões. O grande feito dos dois cineastas aqui estudados foi trazer à vista dois exemplos de mulheres silenciadas a partir de conflitos individuais inseridos em contextos culturais conflitantes. Ainda que consigamos reconhecer e acompanhar as histórias, fica claro que a mulher muitas vezes perde sua voz e força diante dos obstáculos sociais. Sibel tenta se livrar da grande influência do pai e do irmão. Sempre que está em família, ela se cala. Passa a ser a adolescente falante quando se casa com Cahit. E, ao final, volta a ser uma pessoa calada, quando decide ficar com a nova família, com o marido turco, voltando, portanto, às suas raízes culturais, como um destino ao qual estivesse condenada. Diouana é praticamente muda em relação aos patrões. Porém, os seus pensamentos complexos compensam a falta de voz. Para Spivak (2010, p. 66):

5. "Há nódoas de névoas que olho nenhum dissipa" (SEBALD, 1993, p. 39, tradução livre). 
[...] a relação entre a mulher e o silêncio pode ser assinalada pelas próprias mulheres; as diferenças de raça e de classe estão incluídas nessa acusação. A historiografia subalterna deve confrontar a impossibilidade de tais gestos. A restrita violência epistêmica do imperialismo nos dá uma alegoria imperfeita da violência geral que é a possibilidade de uma episteme.

Na busca da recuperação de sua identidade ou, poderíamos dizer, de sua voz, a mulher tem o ímpeto de ir à rua. Diouana, quando quer mudar de vida, sai à procura de trabalho. Ao descobrir que iria para a França, fica ainda mais feliz, porque é uma oportunidade única de ser alguém. A história de Sibel é um tanto inusitada em relação ao casamento. Muitas mulheres do seu âmbito cultural fogem do casamento arranjado ou com pessoas da mesma comunidade. Sibel usa as regras do jogo para criar uma brecha e tentar fugir. Sendo assim, parafraseando Silvia Cardoso Sica (2011), estar na rua é voltar a ser.

A polaridade entre masculino e feminino é um aspecto que se atrela ao silenciamento feminino. Este aspecto não é tão evidente em La Noire de..., exceto pelo fato de Diouana virar o "arrimo da família". Teoricamente, a senegalesa vai à França para poder oferecer uma situação mais confortável à sua família. A turca Sibel, por sua vez, quer ser totalmente independente. Possivelmente, pelo fato de ser um filme mais recente, Contra a parede já apresente a mulher com possibilidades de se manter sozinha.

Em ambos os filmes, porém, há um desejo das protagonistas de ter uma relação amorosa e, de certa maneira, subjugar-se ao domínio masculino. Esse embate entre o ser e o não ser causa prejuízos, como justificado no texto de Oliveira (apud SICA, 2011, p. 86):

As mulheres tentaram a passagem da fronteira do mundo dos homens, arrastando escondidas, as raízes plantadas em casa. Adotaram estilos de vida masculinos sem que os homens se feminizassem. Assim ficaram, entre dois mundos, compatibilizando estilos de vida e modos de comunicação diferentes, recebendo da sociedade uma ordem esquizofrenizante: seja homem e seja mulher. E foi assim que o sonho de igualdade tropeçou no impossível. Porque a um homem se pede que seja única e exclusivamente homem, aquele que representa a regra e o padrão face ao qual a mulher deve ser ao mesmo tempo igual e diferente. Mas ninguém pode ser, ao mesmo tempo, si mesmo e o Outro. 
Ninguém consegue ser, ao mesmo tempo, dois sujeitos diferentes, si mesmo e o Outro. As mulheres que observamos nos filmes franco-senegalês e turco-alemão estudados aqui, apesar de tentarem incorporar algumas características que lhes eram alheias, falharam em seus objetivos iniciais. Acabaram retornando, por vias tortas, às suas culturas de origem, das quais justamente procuravam "escapar", em busca de uma vida melhor e mais livre. Decepcionaram-se, por vezes de forma violenta. Portanto, a sua inserção em instâncias de poder acaba sendo frustrada em todos os sentidos. Resta perguntar qual seria o desfecho dessas trajetórias femininas, caso as suas vozes tivessem sido determinantes nos enredos de suas vidas.

\section{REFERÊNCIAS}

ANDERSON, B. Comunidades imaginadas: reflexões sobre a origem e a difusão do nacionalismo. Trad. Denise Bottman. São Paulo: Companhia das Letras, 2008.

BARTHES, R. A câmara clara: nota sobre a fotografia. Tradução de Júlio Castañon Guimarães. Rio de Janeiro: Nova Fronteira, 1984.

BHABHA, H. (Ed.). Nation and narration. London and New York: Routledge; Taylor \& Francis Group, 2004.

LANGFORD, R. Black and white in black and white. Identity and cinematography in Ousmane Sembène's La Noire de... / Black Girl (1966). Studies in French Cinema, v. 1, n.1, p. 13-21, 2001. Publicado online 3 jan. 2014.

SEBALD, W. G. Die Ausgewanderten. Frankfurt: Eichborn, 1993.

SICA, S. C. A mulher no espelho: aspectos do feminino em A hora da estrela, de Suzana Amaral. Dissertação (Mestrado) - Programa de Pós-Graduação em Estudos Comparados de Literaturas de Língua Portuguesa, Universidade de São Paulo, São Paulo, 2011.

SHOHAT, E.; STAM, R. Crítica da imagem eurocêntrica. Tradução de Marcos Soares. São Paulo: Cosac Naify, 2007.

SPIVAK, G. C. Pode o subalterno falar? Tradução de Sandra Regina Goulart Almeida, Marcos Pereira Feitosa e André Pereira Feitosa. Belo Horizonte: Editora da UFMG, 2010.

\section{FILMOGRAFIA}

GEGEN die Wand. Direção: Fatih Akin. Intérpretes: Birol Ünel, Sibel Kekilli, Catrin Striebeck, Güven Kuraç, Meltem Cumbul, Stefan Gebelhoff e Demir Gökgöl. Música: Alexander Hacke e Maceo Parker. Alemanha/Turquia: Universal, 2004. 1 DVD (121 min.), ficção, color.

LA NOIRE de... Direção: Ousmane Sembène. Produção: André Zwobada. Roteiro: Ousmane Sembène. Intérpretes: Thérese N’Bissine Diop, Anne-Marie Jeline, Robert Fontaine, Momar Nar Sene, Toto. Trilha sonora: Air populaire senégalais. Senegal: Filmi Domirev e Les Actualités Françaises, 1966. 35mm (65 min.), ficção, P\&B. 
Medidas de silêncio e voz: a presença feminina em La Noire de... e em Contra a parede

Fontes ELETRÔNICAS

HÜTTMANN, O. Atemloses Ohnmachtsdrama. Spiegel Online, 12 mar. 2004. Disponível em: <http:// www.spiegel.de/kultur/kino/fatih-akins-gegen-die-wand-atemloses-ohnmachtsdrama-a-290229. html>. Acesso em: 28 jul. 2012.

\section{SOBRE AS AUTORAS}

Fernanda Rios é graduada em Comunicação Social com habilitação em Cinema (Fundação Armando Álvares Penteado) e Letras Português/Alemão (Faculdade de Filosofia, Letras e Ciências Humanas da Universidade de São Paulo) e tem Mestrado em Língua e Literatura Alemã (Departamento de Letras Modernas - Faculdade de Filosofia, Letras e Ciências Humanas da Universidade de São Paulo). Tem experiência na área de literatura alemã, com pesquisa nos seguintes temas: roteiro, cinema alemão, tragédia, Nietzsche.

E-mail: fernandariosdemelo@gmail.com.

Claudia Dornbusch é graduada em Letras - Português-Alemão (Universidade Federal Fluminense), tem Mestrado e Doutorado em Letras/Literatura Alemã (Universidade de São Paulo) e é Livre-docente em Letras/Literatura Alemã pela mesma universidade. É professora aposentada da Universidade de São Paulo. Tem experiência na área de Letras, com pesquisa nos seguintes temas: literatura e cinema, cinema alemão contemporâneo, tradução intersemiótica, tradução e adaptação, tradução e interpretação.

E-mail: claudia.dornbusch@gmail.com.

Recebido em 20 de fevereiro de 2017 e aprovado em 03 de junho de 2017. 